\title{
Relação entre a Atividade Proliferativa do Epitélio e a Resposta Angiogênica Estromal em Neoplasias Intra-Epiteliais do Colo Uterino
}

\author{
Relationship between Epithelial Proliferative Activity and the Stromal Angiogenic \\ Response in Cervical Intra-Epithelial Neoplasias
}

Maria Angélica Maia Gaiotto, Julisa Chamorro Lascasas Ribalta, José Focchi João Norberto Stávale, Marcos Roberto Ymayo, Naira Maria Codá

\section{RESUMO}

\begin{abstract}
Objetivo: quantificar os vasos neoformados e a proliferação do epitélio, por meio dos marcadores imuno-histoquimicos anti-CD34 e anti-PCNA, na neoplasia intra-epitelial do colo do útero.

Métodos: foram incluidas 16 pacientes com NIC III e 16 com NIC II (alto grau), 21 pacientes com NIC I (baixo grau) e ainda 11 pacientes com colos normais (grupo controle). A avaliação das lâminas foi feita por dois observadores, concomitantemente, em 10 campos consecutivos, com aumento de $100 \mathrm{X}$ e de 400X, na região de maior densidade vascular (CD34) e na região de maior atividade proliferativa (PCNA).

Resultados: as médias de células positivas obtidas com o emprego do anti-PCNA em neoplasias intra-epiteliais foram: 78,2\% (NIC III), 52, 1\% (NIC II), 33,3\% (NIC I) e 4,6\% (grupo controle), ao passo que com o marcador vascular anti-CD34 as médias foram: 199, 1 vasos (NIC III), 162,0 vasos (NIC II), 11 1, 7 vasos (NIC I) e 124,4 vasos (grupo controle).

Conclusões: os resultados mostram que os dois marcadores, o anti-PCNA e anti-CD34, são úteis na avaliação da atividade proliferativa e angiogênica, respectivamente. $O$ uso do antiPCNA permite diferenciar as neoplasias intra-epiteliais com mais clareza do que o do antiCD34.
\end{abstract}

PALAVRAS-CHAVE: Neoplasias intra-epiteliais cervicais. Angiogênese. Proliferação celular.

\section{Introdução}

O câncer de colo uterino representa ainda, na atualidade, uma entidade das mais importantes e danosas, constituindo grande problema de saúde pública. Estima-se a prevalência em meio milhão de casos novos ao ano, principalmente em países em desenvolvimento $(\mathrm{WHO})^{1}$. No Brasil, segundo os dados do Instituto Nacional de Câncer (INCA) ${ }^{2}, 21.725$ novos casos foram diagnosticados no ano de 1998, ocorrendo 6.815 óbitos.

$\mathrm{Na}$ última década, múltiplos ensaios sugeriram que o papilomavirus humano (HPV) desempenha papel central na sua etiopatogenia, bem

Universidade Federal de São Paulo. Escola Paulista de Medicina. Programa de Pós-graduação em Ginecologia.

Correspondência: Maria Angélica Maia Gaiotto

Rua Francisco Mariano, 554 - Centro

37130-000 - Alfenas - MG como na de suas lesões precursoras ${ }^{3,4}$.

A história natural desta neoplasia, já bem estabelecida, indica haver a progressão de lesões intra-epiteliais para a doença francamente invasora. Porém, a progressão não é impositiva, podendo ocorrer regressão em alguns casos e, em outros, a persistência da lesão ${ }^{4}$.

O diagnóstico das neoplasias intra-epiteliais e do carcinoma invasor baseia-se nos exames citológico e colposcópico, sempre complementados pelo exame anatomopatológico das biópsias realizadas sob orientação colposcópica.

O padrão vascular do colo uterino representa um dos mais importantes critérios de diagnóstico em colposcopia, método indispensável para localizar as áreas alteradas e orientar as eventuais biopsias ${ }^{5}$.

Hinselmann ${ }^{6}$ descreveu aspectos vasculares associados a alterações epiteliais, hoje co- 
nhecidos como mosaico e pontilhado, sendo o primeiro a mostrar que o carcinoma cervical apresenta modificações vasculares características, que denominou hiperplasia vascular adaptativa. Considerando que as alterações vasculares refletem o início da mudança do metabolismo celular, Stafl e Mattingly ${ }^{7}$ mostraram, na neoplasia intra-epitelial, a compressão dos vasos pré-existentes do estroma pela proliferação celular, formando assim o substrato histopatológico do pontilhado e/ou mosaico.

Entende-se por angiogênese a neovascularização ou formação de novos vasos sangüineos a partir da microvasculatura pré-existente ${ }^{8}$. Sabese que a angiogênese ocorre durante a vida embrionária e também em inúmeros processos fisiológicos e em situações inflamatórias, como também em condições patológicas ${ }^{9}$. Stafl e Mattingly ${ }^{7}$ sugeriram que a neovascularização seria observada em todos os estágios de neoplasia intra-epitelial, sendo um pequeno aumento da densidade vascular já detectado no grau I.

Subseqüentemente, Sillman et al. ${ }^{10}$ observaram que $28 \%$ das pacientes com neoplasia intraepitelial, $50 \%$ das pacientes com carcinoma microinvasor e $100 \%$ das pacientes com carcinoma invasor teriam neovascularização atípica. Utilizando anticorpos anti-fator VIII, Schindler ${ }^{11}$ avaliou a densidade vascular nas neoplasias intraepiteliais escamosas de graus I, II e III. Demonstrou existir uma tendência de aproximação entre as variedades II e III, reforçando assim o conceito de Richart ${ }^{12}$, o qual considerava que as neoplasias intra-epiteliais de graus II e III teriam potencial de evolução semelhante.

Utilizando outro marcador vascular, o antiCD34, mais sensível na avaliação da angiogênese do colo, Calux ${ }^{13}$ concluiu não haver diferença significante entre lesões intra-epiteliais cervicais de baixo e alto grau. O marcador acima referido é uma glicoproteína de $110 \mathrm{kDa}$, presente em células progenitoras hematopoéticas, expressando-se em leucemias mielóide e linfoblástica agudas ${ }^{14}$. Do exposto, pode-se observar que o estudo da neoangiogênese está intimamente ligado ao do desenvolvimento neoplásico.

Por outro lado, recentes ensaios têm relatado a relação entre o potencial maligno dos neoplasmas e a atividade de proliferação celular, usando-se o antígeno nuclear de proliferação celular (PCNA), marcador que pode ser empregado em material em parafina ou naqueles resultantes de punção aspirativa ${ }^{15,16}$. Assim, pormenores sobre a proliferação celular poderiam ser úteis para predizer o potencial metastático, a recidiva e, enfim, o prognóstico em várias neoplasias humanas ${ }^{17}$.

Inicialmente, o PCNA foi identificado como antígeno de proliferação celular in vitro e in vivo, em pacientes com lúpus eritematoso, podendo servir como marcador biológico para o estudo de células em proliferação ${ }^{18-20}$. O PCNA é uma proteina de $36 \mathrm{kDa}$, com papel crítico na fase inicial da proliferação celular, atuando como cofator da enzima DNA polimerase delta. Aparece no núcleo durante a fase G1, imediatamente antes da síntese de DNA, atinge o máximo durante esta fase (S), declinando durante a fase G2 e apresenta níveis não-detectáveis na fase $\mathrm{M}^{21}$.

De modo geral, a literatura concernente tanto às variações de densidade vascular quanto aos diferentes índices de proliferação celular, relacionados com as neoplasias intra-epiteliais escamosas de colo, indica haver comportamentos semelhantes entre as lesões de graus II e III, atualmente consideradas como sendo de alto grau ${ }^{18-22}$.

Para esclarecer a existência de uma possível diferenciação entre as lesões precursoras das neoplasias cervicais, propusemo-nos a estudar a relação entre a angiogênese e o comportamento proliferativo do epitélio, utilizando os anticorpos anti-CD34 e anti-PCNA, nos diferentes graus de neoplasias intra-epiteliais do colo uterino humano. Os objetivos deste estudo são: quantificar a atividade angiogênica nos diferentes graus de neoplasia intra-epitelial do colo uterino, por meio da avaliação imuno-histoquímica para CD34, e diferenciar a densidade proliferativa dos epitélios com neoplasia intra-epitelial de graus I, II e III, pela técnica imuno-histoquímica para PCNA.

\section{Pacientes e Métodos}

Foram selecionados fragmentos histológicos obtidos de 64 pacientes com neoplasias intraepiteliais e de colos sem processo neoplásico, atendidas no Setor de Patologia do Trato Genital Inferior e Colposcopia e na enfermaria da Disciplina de Ginecologia do Departamento de Tocoginecologia da Escola Paulista de Medicina (UNIFESP EPM), no periodo de março de 1994 a agosto de 1998.

Os espécimes foram obtidos por meio de biópsia dirigida sob visão colposcópica, com pinça do tipo saca-bocado ou alça de alta freqüência; conização cervical clássica ou cirurgia com alça de alta freqüência ou cirurgias com retirada total do útero.

A faixa etária variou de 19 a 77 anos completos. Do total de 64 mulheres, 21 tinham NIC I 
(grupo B), 16 NIC II (grupo C) e 16 NIC III (grupo D). As 11 pacientes restantes não apresentavam qualquer processo neoplásico, sendo assim consideradas como controle (grupo A). As lâminas preparadas a partir de tecidos obtidos por biópsias e peças cirúrgicas foram selecionadas do arquivo do Departamento de Patologia da UNIFESP - EPM. O grupo controle (A) foi constituído de pacientes submetidas a procedimento cirúrgico por lesão benigna. Após fixação em solução de formol a $10 \%$ por período de 24 a 48 horas, o material foi desidratado em álcool etílico, diafanizado pelo xilol e incluído em parafina por processador automático de tecido.

\section{Histopatologia}

A seguir foram obtidos três cortes histológicos para cada caso, com micrótomo tipo Minot (American Optical, modelo 820) ajustado para cinco micrômetros, perfazendo 192 espécimes.

Após o processamento histológico e montagem em lâmina de vidro, um dos três cortes de cada caso foi corado pela hematoxilina-eosina (HE) segundo a técnica de Michalany ${ }^{23}$, concluindo-se a montagem entre lâmina e lamínula com Entellan. Os demais foram reservados para o exame imuno-histoquímico.

\section{Imuno-histoquimica}

Para a avaliação imuno-histoquímica foram utilizados anticorpos primários, monoclonais, obtidos por imunização de animais em laboratório com antígenos humanos. Para identificar as células com CD34 empregaram-se anticorpos séricos de camundongos (mouse anti human CD34, Novocastra, clone Q B End 10, lote 07-201, DAKO/ M 7165) na diluição de 1:100. Identificou-se a expressão do PCNA, por meio de anticorpos séricos de camundongos (mouse anti human x PCNA, clone PC 10, DAKO/MO 879/lote 064-305), na diluição de 1:6000. Para ambos os conjuntos usaram-se anticorpos secundários a partir do método estrepto-avidina-biotina-peroxidase (Strepto ABC, Dako, Código KO 492 lote 105[102]), na diluição de 1:500, de acordo com Hsu et al. ${ }^{24}$.

As lâminas histológicas, previamente tratadas com 3-aminopropiltrietoxisilana (APTS), foram colocadas em estufa a $57^{\circ} \mathrm{C}$ por aproximadamente 12 horas, para melhor adesão do tecido. Após a desparafinização e hidratação (xilol-álcoolágua), imersão em tampão citrato $(\mathrm{pH} 6,0)$ e irradiação por microondas na potência máxima por 45 minutos, procedeu-se ao bloqueio da peroxidase endógena, com quatro banhos de água oxigenada a 20 volumes, de cinco minutos cada. Novos banhos em água corrente e em solução de tampão fosfato $(\mathrm{pH} \mathrm{7,4-7,6)} \mathrm{foram} \mathrm{feitos,} \mathrm{precedendo} \mathrm{a}$ imersão em soro albumina bovina a $1 \%$. Depois as lâminas foram incubadas com anticorpo primário em câmara úmida, por cerca de 12 horas, seguindo-se de incubação com o anticorpo secundário por 30 minutos. Após a amplificação das reações, os espécimes foram novamente lavados e revelados com 3-3'-diaminobenzidina por cinco minutos. Para contra-coloração, empregou-se a hematoxilina de Harrys e, finalizando, procedeuse à desidratação, à diafanização e montagem entre lâmina e laminula com Entellan.

As células endoteliais assim tratadas adquiriram coloração acastanhada quando ambos os anticorpos estavam presentes, o que permitiu identificá-las.

Simultaneamente, preparou-se um "controle positivo" para a avaliação da eficácia do anticorpo primário, utilizando-se para tanto espécimes teciduais de amigdalas humanas.

Para a contagem dos vasos nos servimos de microscópio ópticos com aumentos de 100X e 400X. Foram avaliados 10 campos histológicos consecutivos em cada lâmina, perfazendo um total de 640 campos avaliados, tomando-se o cuidado de marcar o último vaso, computado no campo anterior, para não contá-lo duas vezes. Considerou-se ainda como unidade vascular a presença obrigatória de células coradas em castanho margeando o espaço luminal. Os vasos parcialmente identificados, não-contidos por inteiro nos campos analisados, não foram considerados.

Para a contagem das células coradas pelo marcador imuno-histoquímico PCNA, utilizamos programa de análise gráfica por computador, o Imagelab (Softium), no Laboratório de Ginecologia Experimental da Disciplina de Ginecologia da Universidade Federal de São Paulo. Utilizou-se o microscópio óptico com objetiva de 100X para a localização das áreas positivas ao anti-PCNA.

Uma vez localizado, passou-se a utilizar objetiva de 400X, com a qual se contou o número total de células presentes, desde a superficie até a membrana basal, perfazendo um mínimo de 1000 células por lâmina. Do total de células contadas em cada campo, avaliaram-se quantas eram positivas ao marcador imuno-histoquímico PCNA.

Dois observadores independentes, concomitantemente e obedecendo aos critérios já citados, procederam à coleta dos dados. Somente quando houve a concordância de ambos, os dados foram registrados.

\section{Análise estatística}

Para a avaliação dos resultados obtidos com o emprego dos marcadores imuno-histoquímicos 
anti-CD34 e anti-PCNA, inicialmente fez-se análise descritiva dos dados por meio do cálculo de medidas-resumo ${ }^{25}$.

Para a análise inferencial, empregou-se a técnica de análise de variâncias (ANOVA) para comparar as médias dos quatro grupos em relação aos marcadores imuno-histoquímicos anti-PCNA e anti-CD34. Quando a análise de variâncias detectou a existência de diferenças entre as médias para o anti-PCNA e, posteriormente, para o antiCD34, utilizou-se o teste de comparações múltiplas de médias, duas a duas, de Fisher.

Nesta parte da análise foram construídos intervalos de confiança para as médias de cada marcador imuno-histoquimico (anti-PCNA e antiCD34), com coeficiente de confiança de 95\% $(\gamma=$ 0,95), segundo Bravo et al. ${ }^{21}$. Em todos os testes, fixou-se em 0,05 ou $5 \%$ o nivel de rejeição da hipótese de nulidade.

\section{Resultados}

Usando-se o marcador endotelial antiCD34, observa-se que a média de vasos no grupo A (controle) foi de 124,4 (erro-padrão de 15,5 ). No grupo B, neoplasias intra-epiteliais grau I, foi de 111,7 vasos (erro-padrão de 13,0). Já entre as lesões de alto grau, no grupo C (NIC II) a média foi de 162,0 figuras vasculares (erro-padrão de $19,3)$ e no grupo D (NIC III) a média atingiu 199,1 vasos (erro-padrão de 12,1) (Tabela 1 e Figura 1).

Utilizando-se a técnica de análise de variância, concluímos que existem diferenças estatisticamente significantes entre as médias dos grupos avaliados pelo anti-CD34, com $\mathrm{p}<0,001$ (Tabela 1 e Figura 1).

Devido a esta diferença empregamos a técnica de comparações de médias, duas a duas de Fisher, em relação ao anti-CD34, e confirmamos que $\mathrm{A}<\mathrm{D}$ e $\mathrm{B}<\mathrm{D}$.

$\mathrm{Na}$ análise dos resultados obtidos com o antiPCNA, observou-se que a média do grupo A (controle) foi de $4,6 \%$ (erro-padrão de 1,1 ) e no grupo B (NIC I) foi de 33,3\% (erro-padrão de 2,3). Já entre as neoplasias intra-epiteliais de grau II e III o percentual médio foi de $52,1 \%$ (erro-padrão de 3,2 ) no grupo $\mathrm{C}$ e de $78,2 \%$ (erro-padrão de 1,8 ) no grupo D (Tabela 2 e Figura 2). Segundo a análise de variância, concluímos que existe alguma diferença entre as médias de anti-PCNA, com significância estatística $(p<0,001)$. Em decorrência desta diferença e utilizando a técnica de comparações de médias, duas a duas de Fisher, em relação ao anti-PCNA confirmamos serem os grupos diferentes entre si: $\mathrm{A}<\mathrm{B}<\mathrm{C}<\mathrm{D}$.
Tabela 1 - Distribuição dos valores de médias, erros-padrão e resultado da estatística correspondentes ao número de vasos avaliados no grupo controle (grupo A), neoplasia intraepitelial grau I (grupo B), neoplasia intra-epitelial grau II (grupo C) e neoplasia intra-epitelia grau III (grupo D) utilizando-se técnica imuno-histoquímica para identificação de estruturas vasculares com o anti-CD34.

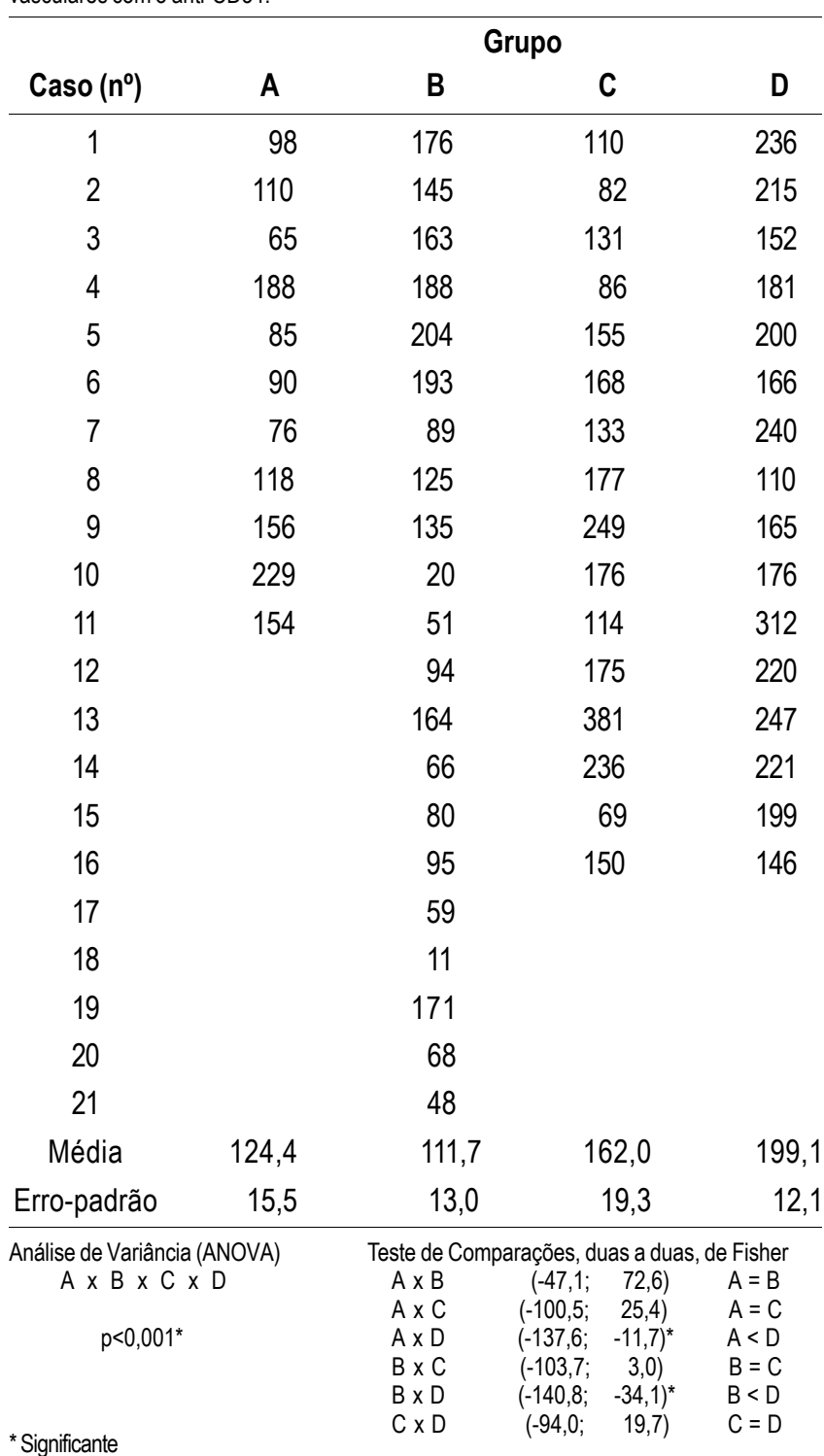

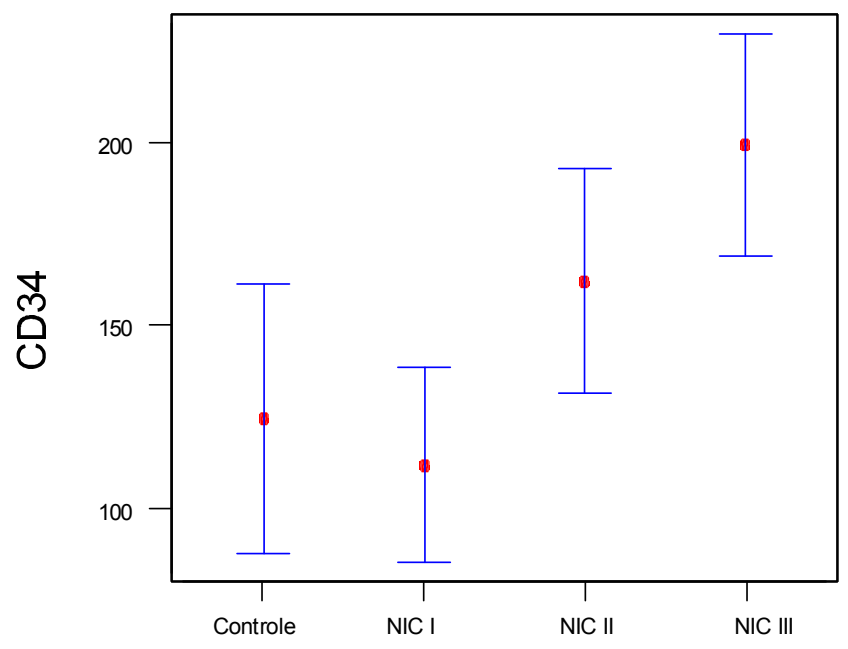

Figura 1 - Representação gráfica da distribuição de intervalos de confiança $(\Upsilon=95 \%)$ para as médias dos quatro grupos avaliados com o marcador imuno-histoquímico anti-CD34. 
Tabela 2 - Distribuição dos valores de médias, erros-padrão e resultado da estatística correspondentes à atividade proliferativa do epitélio ectocervical avaliados no grupo controle (grupo A), neoplasia intra-epitelial grau I (grupo B), neoplasia intra-epitelial grau II (grupo C) e neoplasia intra-epitelial grau III (grupo D) utilizando-se técnica imuno-histoquímica para identificação de proliferação celular com o anti-PCNA.

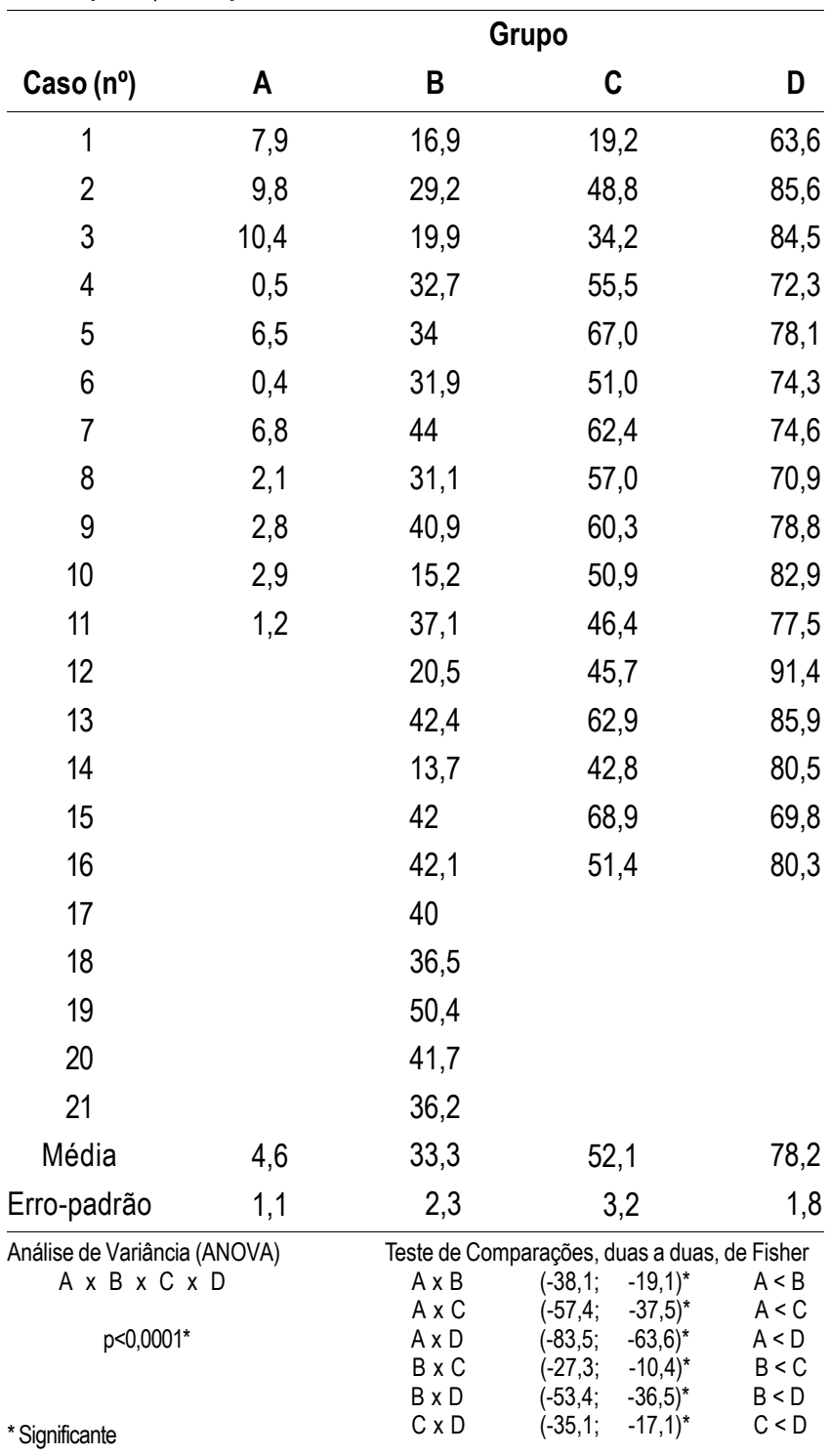

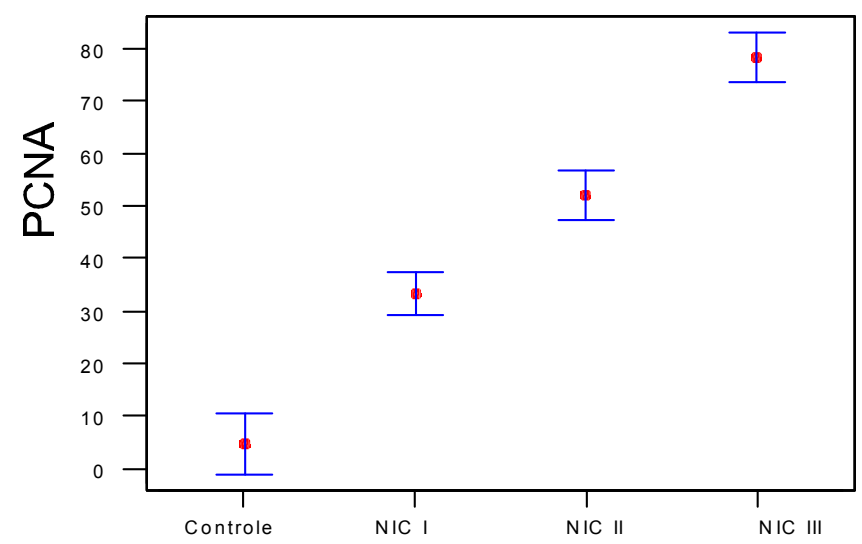

Figura 2 - Representação gráfica da distribuição de intervalos de confiança $(\Upsilon=95 \%)$ para as médias dos quatro grupos avaliados com o marcador imuno-histoquímico anti-PCNA.

\section{Discussão}

A angiogênese e a identificação de proteínas celulares envolvidas no controle da proliferação celular revestem-se de importância para a compreensão dos mecanismos reguladores do crescimento e da transformação celular. Prestam-se ainda para predizer o potencial metastático, a recorrência e o prognóstico não só da paciente com carcinoma cervical mas também com suas lesões precursoras $^{16}$.

Esse fato nos incentivou a quantificar a angiogênese e a proliferação celular no colo normal e nas neoplasias intra-epiteliais, com o intuito de trazer, eventualmente, novos conhecimentos neste campo.

Com relação à contagem dos vasos, observamos sempre a área de maior concentração vascular, segundo a metodologia proposta por Weidner et $a{ }^{26}$ e modificada por Smith-McCune e Weidner ${ }^{3}$ para lesões não-invasivas.

$\mathrm{Na}$ avaliação da atividade proliferativa, consideramos o número de células coradas pelo anti-PCNA, contanto pelo menos 1.000 por lâmina. Todas as lâminas foram submetidas à coloração imuno-histoquímica em uma só oportunidade, para cada um dos marcadores utilizados. Objetivou-se, com esse cuidado, diminuir qualquer irregularidade na coloração em decorrência de variações técnicas.

Considerando a técnica imuno-histoquímica para o CD34 e comparando o número de vasos corados nos grupos A, B, C e D, evidencia-se que as neoplasias intra-epiteliais de grau I não apresentaram diferença estatisticamente significante em comparação ao grau II. Porém, a significância estatística surge quando comparamos o grupo de neoplasias intra-epiteliais de grau I com o de grau III.

Estes resultados mostram uma tendência de aproximação das NIC II ao grupo de lesões de baixo grau e também ao grupo controle. Em contrapartida, o grupo de neoplasias intraepiteliais de grau III distancia-se dos grupos controle e do de neoplasias intra-epiteliais de grau I. Isto nos faz refletir que talvez a passagem para o estado neoangiogênico ocorra na transição de NIC II para III.

Curiosamente, observamos que o erro-padrão no grupo da neoplasia intra-epitelial de grau II foi maior $(19,3)$ do que nos demais grupos. Este dado deixa entrever uma heterogeneidade dos elementos que compõem este grupo, pelo menos do ponto de vista funcional. Assim, as alterações vasculares poderiam representar a primeira evidência morfológica de neoplasia cervical e ocor- 
reriam antes que modificações significantes da morfologia tecidual fossem detectadas ${ }^{7}$.

Notamos que a média de anti-PCNA do grupo B (NIC I) aumentou 7 vezes em relação ao controle, denunciando o início do processo proliferativo. Ainda nessa mesma linha de raciocínio, observamos, em relação ao grupo controle, um aumento de 11 vezes na média do grupo C (NIC II) e de 16 vezes na do grupo D (NIC III); isto mostra, claramente, que houve uma aceleração do processo proliferativo.

O grupo C (NIC II) apresentou aumento da média de anti-PCNA de 1,5 vezes em relação ao B (NIC I). Curiosamente, o grupo D (NIC III) mostra exatamente o mesmo aumento (1,5 vezes) em relação ao C (NIC II). Em outras palavras, o grupo $\mathrm{C}$ revela um comportamento mais constante, diferindo igualmente do grupo $\mathrm{B}$ e do $\mathrm{D}$ no que tange a média. Este fato sugere que talvez a colocação de neoplasia intra-epitelial de graus II e III em um mesmo grupo como preconiza o Sistema Bethesda, de lesões de alto grau, não esteja adequadamente fundamentado.

Ao analisarmos os resultados obtidos com o uso do anti-PCNA observamos que todos os grupos foram significantemente diferentes entre si, porém, evidenciou-se ser o erro-padrão maior entre os constituintes do grupo C (NIC II), revelando provavelmente um processo proliferativo mais variável.

Observamos ainda, nos três grupos de neoplasias intra-epiteliais, o aumento de $63 \%$ da proliferação epitelial no grupo $\mathrm{C}$ em relação ao $\mathrm{B}$ e de $66 \%$ em relação ao D (NIC III). Novamente podese questionar a reunião de NIC II e NIC III em um mesmo grupo, ou seja, de lesões de alto grau. Por outro lado, a angiogênese no grupo C (NIC II) não foi significantemente diferente da do B (NIC I), nem em relação à do D (NIC III). Isto nos leva a imaginar que as neoplasias intra-epiteliais de grau II seriam realmente o marco divisório do potencial de malignização de uma lesão pré-neoplásica, diferindo das neoplasias de grau III.

Os limites deste estudo não permitem desvendar as razões da aparente disparidade entre o aumento da atividade proliferativa e a menor proliferação vascular. Acreditamos que elementos de outras fases do ciclo de divisão, efeitos funcionais, como, por exemplo, ação de fatores de crescimento, ou ainda a indução promovida pelo agente etiológico dessas neoplasias possam ser responsáveis por este achado.

Do exposto é lícito concluir que: a atividade proliferativa consegue diferenciar as neoplasias intra-epiteliais de grau III da neoplasia intraepitelial grau II, ou seja, a neoplasia intraepitelial grau III apresenta maior atividade proliferativa do que a de grau II, havendo significância estatística; as neoplasias intra-epiteliais de alto grau (NIC II e III) mostram densidades vasculares maiores que as neoplasias intraepiteliais de grau I e que os colos normais, havendo significância estatística.

Por sua importância, o tema em apreço, além de justificar esta pesquisa, deve merecer futuras investigações para se tentar estabelecer outros marcadores que melhor exprimam o comportamento dessa tão freqüente neoplasia.

\section{SUMMARY}

Purpose: to quantify the vessels and epithelial proliferation, applying immunohistochemical staining with anti-CD34 as well as anti-PCNA markers, in intraepithelial neoplasia of the uterine cervix.

Methods: in the present study, 16 patients with CIN III, 16 with CIN II, 21 with CIN I and 11 with normal cervix (control group) were investigated. Slide analysis was performed at the same time by two observers, in 10 consecutive sites using $100 \mathrm{X}$ and $400 \mathrm{X}$ magnification, both in the highest vascularization (CD34) and proliferative activity sites (PCNA).

Results: the means obtained with the use of anti-PCNA in intraepithelial neoplasias were: $78.2 \%$ (CIN III), $52.1 \%$ (CIN II), 33.3\% (CIN I) and 4.6\% (control group), while 199.1 vessels (CIN III), 162.0 vessels (CIN II), 111.7 vessels (CIN I) and 124.4 vessels (control group) were quantified using anti-CD34 as a vascular marker.

Conclusion: the results showed that both markers, antiPCNA and anti-CD34, are useful for investigating proliferative and angiogenic activity, respectively. However, anti-PCNA showed better and more accurate results than anti-CD34 in differentiating intraepithelial neoplasias.

KEY WORDS: Cervical intraepithelial neoplasia. Angiogenesis. Cell proliferation marker.

\section{Referências}

1. WHO. World Health Organization. Women's health towards a better world. $1^{\text {st }}$ ed. Geneva: WHO; 1994. p.21-3.

2. INCA. Instituto Nacional de Câncer. Estimativa de incidência e mortalidade por câncer no Brasil 1998. $1^{\text {a }}$ ed. Rio de Janeiro: Pró-Onco/INCA; 1998. 
3. Smith-McCune KK, Weidner N. Demonstration and characterization of the angiogenic properties of cervical dysplasia. Cancer Res 1994; 54:800-4.

4. Syrjänen K. Spontaneous evolution of intraepithelial lesions according to the grade and type of the implicated human papillomavirus (HPV). Eur J Obstet Gynecol Reprod Biol 1996; 65:45-53.

5. Kolstad P. Vascular changes in cervical intraepithelial neoplasia and invasive cervical carcinoma. Clin Obstet Gynecol 1983; 26:93848.

6. Hinselmann H. Diagnostico de los estados precursores del carcinoma de cuello uterino. Rev Med Córdoba 1952; 40:12-5.

7. Stafl A, Mattingly RF. Angiogenesis of cervical neoplasia. Am J Obstet Gynecol 1975; 121:84552 .

8. Folkman J, Klagsbrun M. Angiogenic factors. Science 1987; 235:442-7.

9. Folkman J. What is the evidence that tumors are angiogenesis dependent? J Natl Cancer Inst 1990; 82:4-6.

10.Sillman F, Boyce J, Fruchter R. The significance of atypical vessels and neovascularization in cervical neoplasia. Am J Obstet Gynecol 1981; 139:154-9.

11.Schindler SS. Angiogênese no colo uterino normal, com neoplasia intra-epitelial e com carcinoma invasor por meio do marcador vascular antifatorVIII [dissertação]. São Paulo: Universidade Federal de São Paulo; 1998.

12.Richart RM. Natural history of cervical intraepithelial neoplasia. Clin Obstet Gynecol 1967; 10:748-84.

13. Calux NMCT. Angiogênese na neoplasia escamosa do colo uterino. Estudo imuno-histoquímico comparativo entre dois marcadores vasculares [dissertação]. São Paulo: Universidade Federal de São Paulo; 1998.

14.Fina L, Molgaard HV, Robertson D, et al. Expression of the CD34 gene in vascular endothelial cells. Blood 1990; 75:2417-26.

15. Kamerow HN, Perchick BA, Burstein DE. Immunocytochemical detection of cyclin, a proliferation-associated protein, in cytologic preparations. Acta Cytol 1991; 35:491-6.

16. Hartmann LC, Sebo TJ, Kamel NA, et al. Proliferating cell nuclear antigen in epthelia ovarian cancer: relation to results at secondlook laparotomy and survival. Gynecol Oncol 1992; 47:191-5.

17.Hall PA, Levison DA, Woods AL, et al. Proliferating cell nuclear antigen (PCNA) immunolocalization in paraffin sections: an index of cell proliferation with evidence of deregulated expression in some neoplasms. J Pathol 1990; 162:285-94.

18.Miyachi K, Fritzler MJ, Tan EM. Autoantibody to a nuclear antigen in proliferating cells. J Immunol $1978 ; 121: 2228-34$.

19.Takasaki Y, Deng JS, Tan EM. A nuclear antigen associates with cell proliferation and blast transformation. J Exp Med 1981; 154:1899-909.

20.Mittal KR, Demopoulos RI, Goswami S. Proliferating cell nuclear antigen (cyclin) expression in normal and abnormal cervical squamous epithelia. Am J Surg Pathol 1993; 17:117-22.

21.Bravo R, Frank R, Blundell PA, Macdonald-Bravo H. Cyclin/PCNA is the auxiliary protein of DNA polymerase-delta. Nature 1987; 326:515-7.

22.Karakitzos P, Kyroudes A, Apostolaki C, et al. The evaluation of PCNA/cyclin expression in cervical intraepithelial lesions. Gynecol Oncol 1994; 55:101-7.

23. Michalany J. Técnica histológica em anatomia patológica. $1^{\mathrm{a}}$ ed. São Paulo: Pedagógica e Universitária; 1981.

24.Hsu SM, Raine L, Fanger H. Use of avidin-biotinperoxidase complex $(\mathrm{ABC})$ in immunoperoxidase techniques: a comparison between $\mathrm{ABC}$ and unlabeled antibody (PAP) procedures. J Histochem Cytochem 1981; 29:577-80.

25.Bussab WO, Morettin PA. Estatística básica. $4^{\mathrm{a}}$ ed. São Paulo: Atual; 1987.

26.Weidner N, Semple JP, Welch WR, Folkman J. Tumor angiogeneses and metastasis: correlation in invasive breast carcinoma. N Engl J Med 1991; 324:1-8.

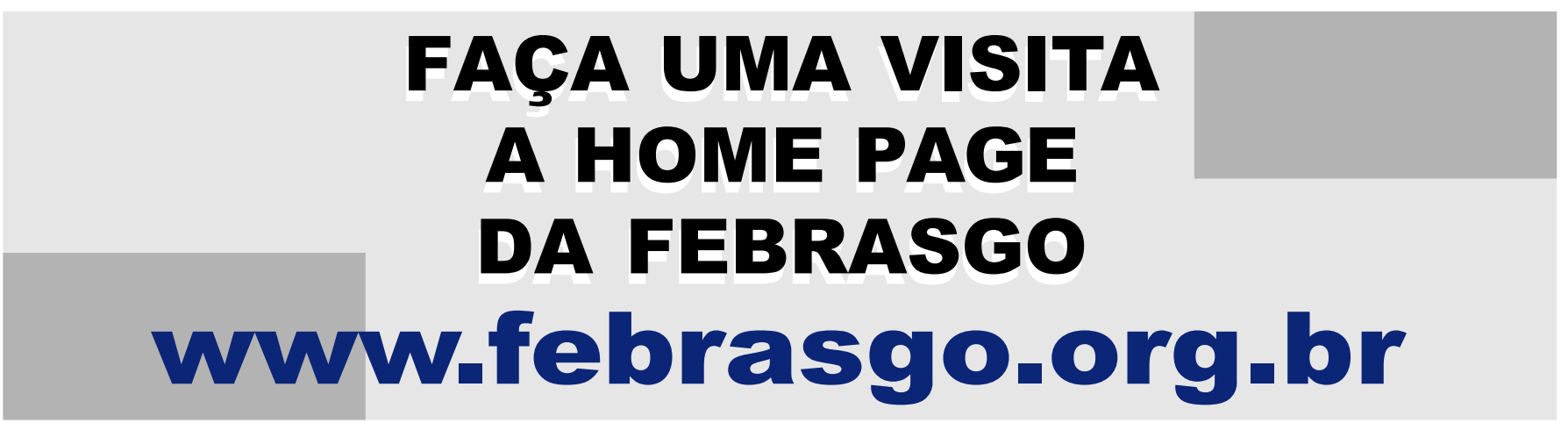

